\title{
CONHECIMENTOS LUDOPEDAGÓGICOS NA APRENDIZAGEM DA NATAÇÃO INFANTIL
}

Recebido em: 08/11/2017

Aceito em: 05/08/2018

\author{
Sergio Bruno Freitas Saraiva ${ }^{1}$ \\ Serviço Social do Comércio (SESC-CE) \\ Fortaleza-CE - Brasil \\ Braulio Nogueira de Oliveira ${ }^{2}$ \\ Universidade Federal do Rio Grande do Sul \\ Porto Alegre - RS - Brasil \\ João Lucas Pinto Matias ${ }^{3}$ \\ Secretaria de Educação do Ceará (SEDUC-CE) \\ Fortaleza-CE - Brasil \\ Bérgson Nogueira de Oliveira ${ }^{4}$ \\ Universidade Federal do Rio Grande do Norte \\ Natal - RN - Brasil \\ André Accioly Nogueira Machado 5 \\ Antônio Ricardo Catunda de Oliveira ${ }^{6}$ \\ Universidade Estadual do Ceará (UECE) \\ Fortaleza - CE - Brasil
}

RESUMO: O presente estudo tem por objetivo analisar o uso dos aspectos lúdicos nas aulas de natação, bem como suas contribuições no processo de ensinoaprendizagem. Trata-se de uma pesquisa qualitativa em que foram entrevistados nove professores de Educação Física que trabalhavam com o ensino da natação infantil. Para análise dos dados, foi utilizada a técnica de análise de conteúdo do tipo análise temática. Os resultados apontam a relevância do lúdico no processo ensinoaprendizagem, que apesar de ser uma prática não rígida, requer tratamento pedagógico, além do fato de que algumas escolas de natação insistem no ensino tecnicista. Conclui-

\footnotetext{
${ }^{1}$ Graduado em Educação Física (UECE). Professor do Serviço Social do Comércio (SESC-CE).

${ }^{2}$ Graduado em Educação Física (UECE). Mestre em Saúde Coletiva (UECE). Doutorando pelo Programa de Pós-Graduação em Ciências do Movimento Humano (PPGCMH-UFRGS). Bolsista Capes.

3 Graduado em Educação Física (URCA). Especialista em Docência no Ensino Superior (IFCE). Professor da Secretaria de Educação do Ceará (SEDUC-CE).

${ }^{4}$ Graduado em Educação Física (URCA). Mestrando pelo Programa de Pós-Graduação em Educação Física (PPGEF-UFRN). Bolsista Capes.

${ }^{5}$ Graduado em Educação Física (Unifor). Mestre em Ciências Fisiológicas (UECE). Doutor em Fisiologia (UECE/UFRJ). Professor Assistente (UECE).

${ }^{6}$ Graduado em Educação Física (Unifor). Mestre em Educação em Saúde (Unifor). Doutor em Ciências da Educação (ULISBOA). Professor Assistente (UECE).
} 
Braulio Nogueira de Oliveira, João Lucas P. Matias,

Bérgson Nogueira de Oliveira, André A. Nogueira Machado e

Antônio Ricardo C. de Oliveira

se que é preciso fomentar a manifestação do componente lúdico como forma de potencializar a fruição, o processo educativo e a participação criativa na cultura.

PALAVRAS CHAVE: Educação Física e Treinamento. Natação. Ensino.

\section{LUDOPEDAGOGICAL KNOWLEDGE IN CHILDREN'S SWIMMING LEARNING}

ABSTRACT: The present study aims to analyze the use of playful aspects in swimming lessons, as well as their contributions in the teaching-learning process. This is a qualitative research, in which were interviewed nine Physical Education teachers who worked with the teaching of children's swimming. To analyze the data, we used the content analysis technique of thematic analysis type. The results point out the relevance of the playful in the teaching-learning process; Which despite being a non-rigid practice, requires pedagogical treatment; And that some swimming schools insist on technical education. It is concluded that it is necessary to promote the manifestation of the ludic component as a way to enhance fruition, the educational process and creative participation in culture.

KEYWORDS: Physical Education and Training. Swimming. Teaching.

\section{Introdução}

O uso dos aspectos lúdicos para o ensino da natação é uma prática que vem ganhando espaço principalmente na iniciação dessa modalidade. As histórias infantis possuem a capacidade de aproximar o professor ao aluno por meio de situações elaboradas a partir dos frutos da imaginação e da criatividade. A criança se harmoniza com o professor, e assim se facilita a relação de confiabilidade. Além de se focar no aprendizado com uma metodologia mais prazerosa e participativa, há uma apreciação do que é ensinado, assim como o que é aprendido (BARBOSA, 2007). De acordo com Machado (1978), há muito tempo já haviam atribuições sobre a importância da perspectiva lúdica para o ensino da natação.

Freire e Schwartz (2005), Oliveira (2009) e Soares, Pagani e Lima (2014) evidenciam em seus estudos a relevância de promover a manifestação do elemento lúdico no processo de ensino-aprendizado da natação. Ressalta-se que o lúdico é aqui 
entendido como elemento da cultura e não somente "em si mesmo" ou em alguma prática específica, podendo ser visto "como produto e como processo; enquanto conteúdo e enquanto forma" (MARCELLINO, 2012, p. 28). Nessa perspectiva, o lazer é um espaço potente para sua manifestação, embora não necessariamente se faça presente, além de que, por ser elemento da cultura, está presente em outros momentos de nossas rotinas (MARCELLINO, 2012).

Diante disso, a natação infantil pode ser entendida como espaço de lazer a qual pode (ou não) produzir a manifestação do elemento lúdico. Sua potência reside em sua característica de criação contínua e ininterrupta, rompendo com a lógica da produtividade e da performance (MARCELLINO, 2012). Sendo assim, é preciso não se restringir a um modelo funcionalista de que o lúdico, na perspectiva da natação infantil, limita-se a facilitar o processo de aquisição das capacidades motoras básicas do meio líquido, mesmo este sendo um elemento presente. Nesse sentido, atribuímos a postura pedagógica de fomentar a manifestação do elemento lúdico da cultura como processo educativo, entendendo a natação infantil como espaço de lazer, de ludopedagogia.

Com o lúdico, é possível inventar um mundo novo sem abandonar a particularidade que é ensinada quando se assume seu papel dentro das aulas de natação. Porém, comumente a esse termo é associado a ausência de seriedade. Isso, às vezes, faz com que o lúdico seja utilizado apenas como prêmio ao final de uma aula bem sucedida, o que descaracteriza o seu real sentido e valor (SILVA, 2011).

Ainda que o lúdico enquanto manifestação cultural ultrapasse questões utilitaristas, há evidências que o apontam como produtivo tanto no âmbito pedagógico como para a saúde. Em um trabalho sobre a intervenção a partir de jogos cantados no processo de ensino-aprendizagem de crianças de três a seis anos que frequentam a 
natação infantil, foram encontrados resultados relevantes no que se refere à aprendizagem (CAVALCANTI, 2016). Há ainda resultados relevantes do uso do lúdico em relação à saúde; em revisão sistemática acerca do risco da natação para crianças com cateteres venosos centrais (CVC), por exemplo, Miller et al. (2013) apontam que a metodologia comum entre os professores é a natação recreativa com foco no lúdico. Nessa lógica, entende-se que o ensino da natação infantil, com base na ludopedagogia manifestação do componente lúdico da cultura enquanto processo educativo -, é um diferencial para o aprendizado das crianças (CAVALCANTI, 2016; FLORÊNCIO et al. 2016; SILVA, 2015; SANTOS; MAFRA, 2007).

Diante do exposto, o presente estudo tem por objetivo analisar a ludopedagogia nas aulas de natação, bem como suas contribuições no processo de ensinoaprendizagem. Para isso, descrevemos a seguir o percurso da pesquisa, a importância do lúdico, o uso da ludopedagogia no ensino da natação infantil e em outros cenários.

\section{Metodologia}

Trata-se de uma pesquisa qualitativa, visto que se buscou a compreensão do significado de uma experiência dos participantes em determinado ambiente, bem como o modo como os componentes se combinam para formar o todo (THOMAS; NELSON; SILVERMAN, 2012).

O cenário do estudo foi o Serviço Social do Comércio (SESC), em Fortaleza, Ceará. Essa instituição foi escolhida por possuir mais de sessenta anos de existência e, desde então, ofertar a modalidade natação, tendo respaldo em se tratando da temática abordada. O SESC possui cerca de 20 horários diferentes para essa prática e, nesse contexto, conta com 26 turmas de natação infantil. 
Foram incluídos na pesquisa os professores com formação em Educação Física atuantes na natação infantil há mais de um ano, por pressupormos que estes possuem um acervo maior de conhecimento teórico e empírico em relação ao tema. Foram excluídos da pesquisa os estagiários e os professores que não atuam com a modalidade. Desse modo, as informações empíricas foram construídas a partir dos relatos de nove profissionais de Educação Física.

A coleta de dados ocorreu por meio de uma entrevista semiestruturada com temas que foram organizados a partir de uma adequação de um roteiro sobre a utilização dos brinquedos no processo de ensino aprendizagem da natação, elaborado por Rocha (2014). A escolha por tal meio se deu por sua assimilação ao nosso objeto e estudo. Esse roteiro nos permitiu perceber, principalmente, acerca do preparo dos professores em relação à ludopedagogia, bem suas significações a respeito do mesmo nas aulas.

Por se tratar de uma pesquisa descritiva, foi realizada a técnica de análise dos dados do tipo análise temática, que, do ponto de vista de Minayo (2007), desdobra-se nas fases de pré-análise, que se refere à seleção dos documentos a serem avaliados, no resgate das hipóteses e dos objetivos iniciais da pesquisa, revisando-as frente ao material colhido e na elaboração de indicadores que guiem a interpretação final; exploração do material ou codificação, que incide na operação de avaliar o texto sistematicamente em função das categorias formadas antes; e tratamento dos resultados obtidos/ interpretação, que remete à submissão das categorias que serão usadas como unidades de análise a operações estatísticas simples ou complexas, dependendo do caso, de forma que possibilitem ressaltar as informações obtidas.

Diante disso, com a análise do material empírico - metodologias de ensino existentes; especificidades de cada turma; e liberdade que os sujeitos relataram ter para 
Braulio Nogueira de Oliveira, João Lucas P. Matias,

Bérgson Nogueira de Oliveira, André A. Nogueira Machado e

Antônio Ricardo C. de Oliveira

ministrarem suas aulas -, foi possível a construção de três núcleos de sentido: (i)

importância do lúdico; (ii) ludopedagogia no ensino da natação infantil; (iii)

ludopedagogia em outros cenários.

A pesquisa contemplou todos os aspectos éticos vigentes e contou com aprovação pelo Comitê de Ética em Pesquisa Envolvendo Seres Humanos da Universidade Estadual do Ceará, com parecer de número 1.414.224.

\section{Importância do Lúdico}

Esse núcleo de sentido aborda a percepção dos profissionais de Educação Física acerca da manifestação do componente lúdico da cultura como forma de potencializar o processo educativo na natação infantil. Ao entender a natação infantil como prática de lazer, identificamos que nem sempre o lúdico está presente, ao passo que expomos, a seguir, a argumentação de alguns dos profissionais.

É extremamente importante, pelo fato das crianças não terem um pensamento técnico das coisas, então a gente tem que trabalhar com o lúdico para atrair a atenção das crianças e assim desenvolver o que tem que desenvolver das técnicas dos nados (Professor 2).

Para criança, é de extrema importância porque o tecnicismo fica muito sacal para criança. Quando a gente procura ensinar através do lúdico a criança tenta aprender e aprende com mais prazer e a tendência de ela faltar e aprender é muito maior (Professor 3).

O lúdico é o que vai atrair a criança, o lúdico faz com que a criança não se desmotive. Com criança, se a gente trabalha muito a técnica, vai chegar uma hora que ela vai estar cansada, ela não vai querer melhorar mais, e não tem uma motivação para ela, [...] o lúdico é o que vai motivar e vai fazê-la aprender também, porque muitas pessoas acham que não aprendem, mas você aprende através do lúdico, com as brincadeiras você aprende [...], porque quando chegar na fase maior de idade, a fase de trabalhar a técnica, ela vai logo se desmotivar com aquilo, vai se desgastar, vai achar que não tem nada atrativo e pronto (Professor 5).

O Professor 5 fala que quando o trabalho é feito com base tecnicista, além de 
Braulio Nogueira de Oliveira, João Lucas P. Matias,

Bérgson Nogueira de Oliveira, André A. Nogueira Machado e

Antônio Ricardo C. de Oliveira

cansá-las e desmotivá-las, não é envolvente e prejudica o aprendizado. De acordo com

Pires, Abreu e Franca (2016), isso ocorre pela mera reprodução fiel do treinamento esportivo, que exclui os menos habilidosos, alinhando-se a uma lógica de performance. Desse modo, o aluno pode ser visto pelo professor como um atleta, e coíbe a manifestação do elemento lúdico da cultura (FINCK, 2011). Ou seja, o professor tornase um técnico e o aluno transforma-se em um atleta.

Por outro lado, é possível identificar na argumentação dos profissionais um viés funcionalista na forma em que alguns abordam a manifestação do lúdico nas aulas, descaracterizando suas premissas - como meio para aquisição de técnicas de nado, exclusivamente, por exemplo. De fato, quando há manifestação do elemento lúdico da cultura, há um aprimoramento do desenvolvimento de habilidades, interpretação, imaginação e criatividade (SILVA, 2011), contudo, a produtividade em detrimento da fruição e criatividade descaracteriza o lúdico.

Silva (2011) coloca que a ludicidade, além de colaborar para o ensino da natação, ao fazer com que os conteúdos técnicos sejam mais bem absorvidos pelas crianças, ela proporciona um clima harmonioso e cativante durante as aulas, o que permite que as crianças se aproximem umas das outras, além de se familiarizarem com o ambiente aquático e com o professor. Argumentação semelhante esteve presente nas falas a seguir:

Eu acho que é muito importante, como eu falei, principalmente para as crianças de menor idade, quatro ou cinco anos, se a gente não proporciona um aspecto lúdico, contar uma história, faz de conta, uma brincadeira, geralmente eles não conseguem prender a atenção, a gente não consegue trazer o aluno para atividade. Eu acho que é essencial, a gente pode sim aliar os aspectos da natação trazendo atividades lúdicas para que eles aprendam, não deixando de aprender e não deixando de brincar, que é uma coisa muito importante para eles (Professor 4). 
Braulio Nogueira de Oliveira, João Lucas P. Matias,

Bérgson Nogueira de Oliveira, André A. Nogueira Machado e

Antônio Ricardo C. de Oliveira

Aprender de uma forma mais (...), não sei se essa é a palavra certa, mais amena, aprender sem saber que você está aprendendo é muito mais prazeroso. Você trazer parte de sua vida cotidiana para o exercício lúdico, para uma história, para qualquer coisa que traga para um contexto, que te leve para um outro mundo, usando os modelos da nossa vida real, só acrescenta, tanto no prazer, como na parte motora, como na parte social (Professor 7).

Conforme a fala do Professor 7, torna-se mais prazeroso o ensino do lúdico por proporcionar o aprendizado mesmo quando, para os praticantes, a prática educativa não é o fim (e sim a fruição). Além disso, são utilizados exemplos da vida cotidiana, fato que potencializa a prática educativa. Há, portanto, influência nas ações e comportamentos, o que leva os alunos a seguirem normas e valores que são fomentados (POMAR; CARLOS NETO, 2003). Além da aprendizagem da técnica e tática do esporte, o caráter lúdico pode potencializar o desenvolvimento da personalidade da criança (SILVA, 2015). Assim, a ludopedagogia ganha relevo.

Com certo saudosismo, os participantes destacam uma mudança nas práticas de lazer, ao considerarem que, na contemporaneidade, as brincadeiras "na rua" não mais existem. Sendo compreendida como espaço privilegiado para manifestação do componente lúdico, de acordo com os profissionais, a natação infantil exerce parcialmente esse lugar.

$\mathrm{Eu}$ acho que o lúdico é uma peça muito importante para nós professores e, principalmente, para as crianças. Para nós, porque nos ajuda a prender a atenção delas, faz com que elas participem, elas tenham interesse pela aula, enfim, nos ajuda a ter tranquilidade durante a aula. Para elas é bom porque elas ficam atentas, querem saber o final da história criada pelo professor, criam mundos imaginários, se divertem, muito diferente da realidade que eles têm em casa ou na escola. Olha só, antigamente as crianças tinham onde brincar, ficavam brincando no meio da rua, corriam, pulavam, enfim, as crianças eram felizes. Hoje em dia se você for ver, quase toda criança só quer saber de assistir, jogar videogame, ficar nos celulares, o mundo que elas têm é o delas mesmo, não interage com os coleguinhas. Aí se a gente não proporciona nenhum momento de ludicidade para elas, aí pronto, a gente acaba com a infância delas 


\section{(Professor 9).}

Percebemos, dessa forma, a importância da manifestação do lúdico nas aulas, visto que estas podem atrelar a natação infantil como espaço de lazer que anteriormente era vivido "na rua". Atividades que envolviam mais fortemente o movimento corporal, como brincadeiras de rua, atividades relacionadas à cultura popular, vêm sendo substituídas, ou tem ficado em segundo plano, se comparadas a evoluções tecnológicas, como os jogos eletrônicos, celulares, entre outros. Santos et al. (2014), por exemplo, destacam efeitos prejudiciais na saúde, na educação e nos comportamentos sociais, caso o uso das mídias seja demasiado.

Dessa forma, a natação infantil, em uma perspectiva ludopedagógica, pode favorecer o desenvolvimento das crianças, aspecto que envolve o uso racional das mídias digitais. Nesse sentido, é importante que o professor esteja ciente da aplicabilidade da proposta ludopedagógica nas suas aulas, fomentando a manifestação do elemento lúdico da cultura.

\section{Ludopedagogia no Ensino da Natação Infantil}

Os relatos apontam para uma ludopedagogia na condução das aulas, bem como algumas repercussões de seu uso. Desse modo, colaboramos com Almeida (1995, p.11) quando nos explica que "[...] a educação lúdica é uma ação inerente na criança e aparece sempre como uma forma transacional em direção a algum conhecimento [...]”; entendendo, porém, que o favorecimento da manifestação do lúdico deve ser uma postura pedagógica do professor, incluindo objetivos educacionais. Nessa perspectiva, ludopedagogia é mais que um mero "passatempo", sendo pertinente que seja algo planejado e intencionado pelo professor (GUMIERE; TREVISO, 2016). A rigor, 
Braulio Nogueira de Oliveira, João Lucas P. Matias,

Bérgson Nogueira de Oliveira, André A. Nogueira Machado e

Antônio Ricardo C. de Oliveira

entende-se que as práticas que envolvem a manifestação do lúdico tocam o universo

infantil, o que facilita o ato pedagógico. De acordo com Vigotsky (1994, p. 82):

A criança que sempre participou de jogos e brincadeiras grupais saberá trabalhar em grupo; por ter aprendido a aceitar as regras do jogo, saberá também respeitar as normas grupais e sociais. É brincando bastante que a criança vai aprendendo a ser um adulto consciente, capaz de participar e engajar-se na vida de sua comunidade.

Nesse rumo, os professores reiteram em seus relatos o fomento à manifestação do lúdico em suas práticas pedagógicas de natação infantil, tendo aquele como central nas aulas.

O lúdico só ajuda, porque com crianças deve ser trabalhado o lúdico, para poder atraí-la para aquela atividade; se a gente trabalhar muito a parte técnica, eles acabam que não é atraente para criança isso; aí acaba que eles vão se dispersar, vão cansar, e acaba que não faz o restante da aula. Acho que o lúdico é superimportante e, ao meu ver, com criança, tem que ser trabalhada sempre com o lúdico e um pouco de técnica também, que se ele visa melhorar, quando estiver maior para se trabalhar essa parte da técnica dele, tem que trabalhar um pouco, mas sempre focando no lúdico (Professor 5).

Com crianças, eu acho muito bacana usar jogos, jogos de cooperação. Eu digo isso porque dentro da minha atividade, especificamente, tem uma pessoa com deficiência, e fazer com que as crianças participem do processo de aprendizagem, não só da que tem deficiência, mas deles entre si, eu vejo que é mais proveitoso, mais bacana, fica um clima bacana, tanto dentro da equipe, como para o aprendizado deles, pois eles se ajudam mutuamente (Professor 7).

Diferente das escolinhas de natação, a gente tem um fundo teórico, aquele de aprendizado da natação através do lúdico, e eu entendo o lado SESC em utilizar a ludicidade e até gosto que seja na ludicidade. Eu acho que para crianças de três até seis anos, que é a turma daqui, é algo atrativo para eles; apesar do meio liquido já ser algo lúdico, você trazendo junto com isso algumas brincadeiras com um fundo de teoria, acho que para eles vai ser muito mais fácil de captar (Professor $8)$.

Os sujeitos abordam que, em suas práticas, a manifestação do lúdico se faz

presente em diversos momentos. O Professor 5, por exemplo, afirma que independentemente da faixa etária da turma para a qual ministrará uma aula, deve-se 
fomentar essa manifestação, pois assim as crianças serão mais atenciosas em relação à realização das atividades práticas, ou seja, é algo sedutor para elas. Percebemos que é possível relacionar lazer e processo educativo em cenários não escolares, mesma defesa feita por Marcellino (2012), ainda que a ênfase de sua proposta seja para essa relação no âmbito escolar.

O Professor 7 argumenta, inclusive, a potencialidade dessa postura pedagógica como forma de inclusão. Esta precisa ser entendida além de não exclusão, na medida em que, numa perspectiva ludopedagógica, é preciso uma participação cultural efetiva. Nesse sentido, Mazzotta e D’Antino (2011) vislumbram o elemento lúdico como potencializador da inclusão. Bruhns (1993) destaca que essa postura avança numa dimensão humana de convívio com o meio social. Lopes $(2012$, p. 9) argumenta que “[...] toda criança aprende brincando", semelhante à fala do Professor 8, ao relacionar o lúdico e o processo educativo.

A ludicidade deve ser utilizada como estratégia de ensino, principalmente nas faixas etárias menores, pois, nessa fase, as crianças procuram descobrir o mundo que as cercam e, por isso, movimentam-se demasiadamente (TAZINAZZO, 2012). Isso permite uma aproximação entre o imaginário e o mundo real, que implica o aprendizado acerca de sentimentos, frustrações, o pensamento, a concentração, estímulos, a autoconfiança, entre outros valores importantes (VIGOSTKY, 1994). Entende-se, portanto, que o trabalho com ênfase na manifestação do elemento lúdico da cultura auxilia no desenvolvimento da criatividade, sensibilidade e interatividade, além de proporcionar bem-estar aos educandos (NASCIMENTO et al. 2012; TAZINAZZO, 2012).

Contudo, ainda que com robusto referencial que aponta para a potência do 
Braulio Nogueira de Oliveira, João Lucas P. Matias,

Bérgson Nogueira de Oliveira, André A. Nogueira Machado e

Antônio Ricardo C. de Oliveira

fomento à manifestação do elemento lúdico da cultura nas práticas de lazer, inclusive na

natação infantil, Linhaio (2011) aponta que existe no meio docente uma ideia equivocada que a coloca como contrária ao ensino-aprendizagem, pois desconsideram sua possível relação com o processo educativo. De acordo com as entrevistas, os sujeitos indicam que é preciso saber a "hora certa" para fomentar essa manifestação:

Tem que saber a hora exata do lúdico dentro da aula e a hora de parar, porque se voltar só para o lúdico e eles associarem que estão vindo para fazer natação só para brincar, então assim fica a desejar, [...], sempre trazendo para o lúdico de forma simples para que eles entendam. Então, é sempre importante ver essa questão da hora de parar: "agora vamos aqui, senão vocês não vão conseguir passar para outra piscina, não vão conseguir desenvolver; então vamos quem quer passar para outra piscina" - vamos incentivar, sempre incentivando os alunos a fazerem as atividades! (Professor 1).

Você sabendo administrar a ludicidade, ele é um fator positivo; ele vira fator negativo quando o professor perde o controle da turma, em que sentido, do lúdico voltado para o aprendizado, ele esquece do aprendizado e fica só lúdico; então é questão de controle e autonomia do professor na aula, mas eu sou super a favor a ludicidade na aula, principalmente para crianças, porque criança, se ela não estiver se divertindo, para ela não está legal, então é uma forma de trabalho muito interessante (Professor 6).

Os participantes apontam para a necessidade de atrelar a manifestação do lúdico ao processo educacional, ainda que desconsiderem a relevância do lúdico como fim em si mesmo. Nesse sentido, o Professor 1 também fomenta o lúdico com muito cuidado, para não deixar transparecer que o ambiente da natação é somente de brincadeira e, nessa ótica, em tese, a aula não alcança seus objetivos. Queiroz (1998) e Scaglia e Souza (2004) destacam que é de responsabilidade do docente moldar os aspectos educacionais de suas aulas, através de estímulos de criatividade, de valores e entre outros.

Dessa forma, cabe ao professor de Educação Física dominar estratégias pedagógicas que favoreçam a manifestação do elemento lúdico, articulando este ao 
Braulio Nogueira de Oliveira, João Lucas P. Matias,

Bérgson Nogueira de Oliveira, André A. Nogueira Machado e

Antônio Ricardo C. de Oliveira

processo educativo (MARCELLINO, 2012), transformando o conhecimento em algo

divertido e prazeroso. Colaboramos com a ideia de que no momento de aprendizagem

de certos movimentos, as crianças brincam com aquilo e, desse modo, possibilitam o desenvolvimento de diversas formas de executá-lo (VENDITTI JÚNIOR; SANTIAGO, 2008). A ludopedagogia promove tanto uma maior fruição em relação à prática quanto ao ensino da natação de modo mais específico.

\section{Ludopedagogia em Outros Cenários}

Nesse núcleo de sentido os professores alertam para a realidade de outros cenários - que não o SESC, em Fortaleza, Ceará - em que, muitas vezes, o fomento da manifestação do elemento lúdico, por vezes atrelado ao processo educativo (conforme a proposta por eles desenvolvida), não integra a postura pedagógica.

Aqueles locais que são escolinhas, geralmente eles trabalham a técnica; eu já até estagiei em locais assim, e era o técnico-técnico; tinha crianças lá de dez anos, onze anos, que não tinha negócio de lúdico, não, era só o técnico: um dia, resistência, outro dia, usava o palmar para se trabalhar a resistência, né? Aí colocava o pé de pato para ajudar também na velocidade e tudo, não existia, mas nesses que não são trabalho técnico, tipo esses clubes e academias menores, acho que as aulas lá são feitas em cima do lúdico (Professor 5).

Eu vejo que, hoje, existe um valor agregado à empresa que você trabalha. Eu acho muito difícil você falar assim: "Ah! Aquela pessoa não usa!". Eu costumo ver assim: aquela empresa, aquele lugar não tem aquela política. Por exemplo, nessas escolinhas de alto rendimento, esses clubes que buscam o aprendizado somente técnico, nesses acho que por mais que existisse o interesse, não seria possível existir o conteúdo lúdico. Então, eu vejo que é muito mais o contexto, princípio do local, do que exatamente o professor em si (Professor 7).

Enquanto professores, entende-se que apenas ensinar a nadar não é suficiente (DAMASCENO, 1997), pois isso seria enaltecer apenas o produto final. Reiteramos a fala dos professores acerca da relevância do processo pedagógico, bem como o fim além do ensinar a nadar. Desse modo, criticamos as formas de ensino na natação restrito ao 
desenvolvimento do aspecto motor.

Identificamos que o Professor 7 aponta que não somente alguns pais desejam formar futuros nadadores profissionais, mas também algumas escolas/clubes de natação. Essa perspectiva de trabalho afeta diretamente na forma com que o lúdico se manifesta nesses cenários. Soares, Miskey e Martins (2010) realizam uma crítica a isso, ao argumentarem que em alguns locais que oferecem o ensino da natação, os pais desejam que os filhos aprendam a nadar em alto nível, diferentemente da intenção das crianças.

Essas iniciativas tomadas por pais e/ou técnicos e a antecipação de etapas de desenvolvimento, com a especialização precoce, pode promover, em primeira análise, a ausência de satisfação em praticar natação, fato este que pode reduzir a adesão de iniciantes infantis. Ou seja, a ludicidade, especialmente nessa fase, é fundamental, pois a partir dela é possível elencar capacidades de lidar com o mundo (BARBOSA, 2007).

Outro fator que dificulta a aplicação dos elementos lúdicos nas aulas, possivelmente existente em outros contextos, é o fato de que as turmas possuem crianças com idades e níveis diferentes de aprendizado. Tal afirmação pode ser identificada na fala do Professor 1:

[...] é bem difícil, só em clubes ou academias que sejam mais específicas para isso, só para aquela faixa etária, como o SESC, mais para o lado infantil. Porque tem turma, em muitos locais, que às vezes é misturado: tem um menorzinho, com um maior que tem de dez a doze anos (Professor 1).

Nesse raciocínio, é necessário percebermos a forma através qual a heterogeneidade aparece no local de ensino. Há dificuldades em relação ao ensino pelo professor, pois de acordo com Martins (2014), é quase impossível que um docente perceba a turma em sua total heterogeneidade, analise o nível de cada um e, assim, determine o que aquela precisa aprender; para além disso, faça com que esse 
Braulio Nogueira de Oliveira, João Lucas P. Matias,

Bérgson Nogueira de Oliveira, André A. Nogueira Machado e

Antônio Ricardo C. de Oliveira

aprendizado seja, de fato, efetuado. Bruhns (1993) argumenta que o profissional deve proporcionar um ambiente democrático em relação às práticas lúdicas e de lazer, e dessa forma, poderá haver uma maior participação de todos. O que percebemos é que tal democratização se torna, por vezes, desconsiderada, principalmente em práticas tecnicistas.

Os professores indicam que, mesmo em alguns contextos em que a técnica é privilegiada, a manifestação do elemento lúdico pode ser manifestada, caso seja de interesse do professor, conforme se nota nas falas a seguir.

Hoje em dia, é possível se trabalhar facilmente com a ludicidade, está se investindo muitos recursos nessa questão da natação infantil com ludicidade, a quantidade de escolinhas de natação, de pessoas que trabalham com isso, assim, tá crescendo; tá tendo uma questão de uma mobilização em relação a isso, os próprios pais estão entendendo a necessidade de colocar as crianças nesse tipo de atividade, e eu vejo que realmente está bastante abrangente (Professor 6).

Vejo motivações pessoais, têm pessoas que gostam muito mais de trabalhar com o lúdico, e vejo que têm pessoas que realmente não gostam e acham que é muito mais fácil trabalhar naquela linha formal. E na minha cabeça, isso é muito pessoal mesmo, também desestimulante; [...] a proposta que um jogo tem uma resposta diferente e, de repente, você tem que trabalhar em cima daquela diferença é uma coisa que dá muito mais trabalho, e muitos não querem esse trabalho. Eu vejo que hoje existe motivação, e existe interesses. Cabe ao profissional, hoje, agregar os interesses às suas motivações pessoais, então eu não consigo generalizar isso daí (Professor 7).

Ao analisar o que foi exposto, observa-se, na fala do Professor 6, que o trabalho através da ludicidade está sendo cada vez mais valorizado, tanto por pais quanto pelos locais que oferecem a modalidade, pois há maiores investimentos em recursos para que a natação se torne mais atrativa para os pais e seus filhos. Na perspectiva de Gerster e Brondani (2012), o lúdico oferece a motivação necessária e suscita emoções positivas, as quais, segundo o autor, são as maiores responsáveis pela prática de qualquer atividade que é realizada na infância, pois associa a alegria e satisfação ao ensino- 
aprendizado.

Contudo, entende-se que para a manifestação do elemento lúdico da cultura, no contexto do lazer, de modo mais amplo (não somente na natação infantil), é preciso o fomento público à constituição de espaços apropriados. As pessoas com deficiência, por exemplo, possuem dificuldade para a prática de lazer em locais adequados (BRUHNS, 1993). Desse modo, é fundamental o investimento de escolas, clubes e dentre outros espaços específicos para que o público, não apenas infantil, compareça em maior número.

\section{Considerações Finais}

Baseado nas discussões, esta pesquisa permitiu uma melhor compreensão acerca de como os participantes do estudo abordam o elemento lúdico da cultura no processo educativo, especialmente na natação infantil. Ainda que, por vezes, o destaque tenha se dado com caráter funcionalista, descaracterizando, portanto, o lúdico, este tem centralidade na postura pedagógica dos professores. Romper com uma perspectiva restritivamente funcionalista remete a pensar que o lúdico, como elemento da cultura, não é mera ferramenta para o processo educativo, mas possui fim em si mesmo. Contudo, a manifestação do lúdico precisa ser fomentada, sendo a natação infantil (como prática de lazer) espaço privilegiado para sua ocorrência, sendo preciso ainda um segundo esforço pedagógico para condicionar sua relação com o processo educativo, seja para o ensino da natação, de modo mais restrito, ou para a vida, de modo mais amplo.

Apesar da relevância atribuída pelos professores à manifestação do elemento lúdico da cultura, em uma postura ludopedagógica, com a ressalva a algumas 
concepções ainda restritas (vinculadas a um modelo "funcionalista"), os mesmos demonstram uma preocupação com o ensino da natação infantil em outros cenários, em que o ensino da técnica reduz as possibilidades de manifestação do elemento lúdico da cultura. Essa preocupação esteve centrada na metodologia utilizada em algumas escolas de natação, em que a lógica da performance restringe a dimensão do lúdico. A manifestação do lúdico em cenários que enfatizam a competição pode, inclusive, ser vislumbrada como sinônimo de perda de tempo, desconsiderando sua potencialidade. Contudo, reconhecendo os limites desta pesquisa, ressaltamos que se trata do pensamento de professores que atuam em outro contexto (e não em clubes que visam à competição), sendo necessários novos estudos com ênfase na análise em relação ao lúdico nesses locais.

Diante do exposto, conclui-se que é preciso fomentar a manifestação do componente lúdico da cultura, justamente por promover maior fruição durante as aulas e por potencializar o processo educativo. Assim, é possível possibilitar maior participação na cultura, sobretudo de modo criativo.

\section{REFERENCIAS}

ALMEIDA, P. N. Educação lúdica: técnicas e jogos pedagógicos. São Paulo: Loyola, 1995.

BARBOSA, G. S. Estratégias motivacionais: possibilidade de inclusão do lúdico no processo de ensino aprendizagem da natação. 2007. 65 f. Monografia (Licenciatura em Educação Física). - Departamento de Educação Física da Faculdade de Ciências, Universidade Estadual Paulista, Bauru, 2007.

BRUHNS, H. Recreação e lazer: uma questão complexa. Motrivivência, Florianópolis, v. 6, n.4, p. 189-191, jun, 1993.

CAVALCANTI, I. A Cantiga como instrumento facilitador no processo de ensino aprendizagem de crianças de 3 a 6 anos em aulas de natação infantil. 2016. $39 \mathrm{f}$. Trabalho de Conclusão de Curso (Licenciatura em Educação Física). - Centro de 
Braulio Nogueira de Oliveira, João Lucas P. Matias,

Bérgson Nogueira de Oliveira, André A. Nogueira Machado e

Antônio Ricardo C. de Oliveira

Ciências da Saúde, Universidade Federal do Rio Grande do Norte, Natal, 2016.

DAMASCENO, L. G. Natação, psicomotricidade e desenvolvimento. Campinas: Autores Associados, 1997.

FINCK, S. C. M. A Educação Física e o esporte na escola: cotidiano, saberes e formação. Curitiba: Ibpex, 2011.

FLORÊNCIO, E. C., et al. A utilização da cooperação e da competição na aprendizagem da natação para crianças de 06 a 12 anos. Coleção Pesquisa em Educação Física, São Paulo, v. 15, n. 3, p. 7-14, jun/jul, 2016.

FREIRE, M.; SCHWARTZ, G. M. O papel do elemento lúdico nas aulas de natação. EFdesportes.com, Buenos Aires, v. 10, n. 86., p. 1-4, jul., 2005.

GERSTER. G.; BRONDANI. V. R. Natação Infantil, Ludicidade e os Aspectos metodológicos. In: XVII Semana de Iniciação Científica da UNICENTRO, v.1, n. 1. 2012, Guarapuava. Anais... Guarapuava: UNICENTRO, 2012.

GUMIERE, F. A; TREVISO, V. C. A importância do lúdico para o desenvolvimento da criança: o brincar como ferramenta de aprendizagem na Educação Infantil. Cadernos de Educação: Ensino e Sociedade, São Paulo, v. 3, n. 1, p. 66-80, 2016.

LINHAIO, L. Educação física na escola: Relação entre ludicidade e o processo de ensinar e aprender. 2011. 42 f. Monografia (Graduação em Educação Física) do Departamento de Estudos do Movimento Humano, Universidade Estadual de Londrina, Londrina, 2011.

LOPES, L. M. Ludicidade: Uma alternativa para a Educação Inclusiva no Ensino Regular. 2012. 56 f. Trabalho de conclusão de curso (Especialização em Educação: Métodos e Técnicas de Ensino). Universidade Tecnológica Federal do Paraná, Medianeira, 2012.

MACHADO, D.C. Metodologia da Natação. 2. ed. São Paulo: EPU, 1978.

MARCELlinO, N. C. Pedagogia da animação. 8. ed. Campinas: Papirus, 2012.

MARTINS, M. C. Turmas heterogêneas no ensino superior: um desafio para o professor e para o aluno. European Scientific Journal, v. 1, p. 242-249, set, 2014.

MAZZOTTA, M. J. S; D’ANTINO, M. L. F. Inclusão social de pessoas com deficiências e necessidades especiais: cultura, educação e lazer. Saúde e Sociedade, São Paulo, v. 20, n. 2, abr/jun, 2011.

MILLER, J. et al. Going with the flow or swimming against the tide: Should children with central venous catheters be allowed to go swimming? Nutrition in clinical practice, Dallas, v. 29, n. 1, p. 97-109, fev., 2013. Disponível em: https://onlinelibrary.wiley.com/doi/full/10.1177/0884533613515931. Acesso em: 13 nov. 2018. 
Braulio Nogueira de Oliveira, João Lucas P. Matias,

Bérgson Nogueira de Oliveira, André A. Nogueira Machado e

Antônio Ricardo C. de Oliveira

MINAYO, M. C. S. O desafio do conhecimento: pesquisa qualitativa em saúde. São Paulo: Hucitec, 2007, 269p.

NASCIMENTO, R. M. et al. Lúdico com ferramenta pedagógica no processo ensino aprendizagem. Revista perspectivas online: biológicas e da saúde, Campos dos Goytacazes, v. 5, n. 2, p. 23-30, abr/jun, 2012.

OLIVEIRA, L. W. de. Nadando com alegria: a ludicidade como forma de aprendizagem na natação. 2009. Universidade Vale do Itajaí. Disponível em: http://few.universoef.com.br/container/gerenciador_de_arquivos/arquivos/160/nadandocom-alegria.pdf. Acesso em: 01 fev. 2015.

PIRES, F. P; ABREU, J. R. G; FRANCA, R. G. Educação Física e esporte: o esporte na escola e da escola nas aulas de Educação Física. EFdesportes.com, Buenos Aires, v. 21, n. 219, ago, 2016.

POMAR, C.; CARLOS NETO. Percepção da apropriação e do desempenho motor de gênero em atividades lúdico-motoras. In: CARLOS NETO (Org). Jogo \& desenvolvimento da criança. Cruz Quebrada: FMH, 2003.

QUEIROZ, C. A. Recreação aquática. Rio de Janeiro: Sprint, 1998.

ROCHA, K. F. da. A utilização dos brinquedos no processo de ensino aprendizagem da natação. 2014. 45 f. Monografia. (Graduação em Educação Física) - Departamento Acadêmico de Educação Física, Universidade Tecnológica Federal do Paraná. Curitiba, 2014.

SANTOS et al. Vivendo este mundo digital: impactos na saúde, na educação e nos comportamentos sociais. Artes Médicas, Porto Alegre, v. 19, n. 3, p.991-993, mar, 2014.

SANTOS, M. A. M dos; MAFRA, J. M. Metodologia da natação: Analisando os métodos, princípios e conteúdos de ensino. In: XV CONBRACE e II CONIC POLÍTICA CIENTÍFICA E PRODUÇÃO DO CONHECIMENTO. 14, 2007, Recife. Anais... Recife: CBCE, 16 a 21 de setembro de 2007. (CD-ROM).

SCAGLIA, A. J.; SOUZA, A. Pedagogia do esporte. Comissão de Especialistas-ME. Dimensões pedagógicas do esporte. Brasília: Unb/Cad, 2004.

SILVA, M. P. A importância do lúdico na Educação Infantil. 2015. 49 f. Trabalho de conclusão de curso. (licenciatura em pedagogia). Universidade Estadual da Paraíba. Paraíba, 2015.

SILVA, S. C. da. O lúdico no ensino da natação para crianças no município de criciúma/sc. 2011. 41 f. Monografia (Graduação em Educação Física) - Universidade do Extremo Sul Catarinense, Criciúma, 2011.

SOARES, A. R.; MISKEY, D. H.; MARTINS. P. Aprendizagem na natação infantil de 3 a 6 anos e os benefícios da ludicidade. WebArtigos.com. 12 nov. 2010. Disponível em: http://www.webartigos.com/artigos/aprenddizagem-na-natacao-infantil- 
SOARES, D. V.; PAGANI, M. M.; LIMA, F. S. Iniciação a natação para crianças. Revista Científica da Faculdade de Educação e Meio Ambiente, Ariquemes, v. 5, n. 2, p. 98-114, jul./dez., 2014.

TAZINAZZO, K. O lúdico como estratégia de ensino nas aulas de Educação Física. 2012. 38 f. Monografia (Especialização em Educação) - Universidade Tecnológica Federal do Paraná, Medianeira, 2012.

THOMAS, J. R.; NELSON, J. K.; SILVERMAN, S. J. Métodos de pesquisa em atividade física. 6. ed. Porto Alegre: Artmed, 2012. 478p.

VENDITTI JÚNIOR, R.; SANTIAGO, V. Ludicidade, diversão e motivação como mediadores da aprendizagem infantil em natação: propostas para iniciação em atividades aquáticas com crianças de 3 a 6 anos. EFDeportes.com, Buenos Aires, v. 12, n .117 , fev. 2008.

VIGOTSKY, L. S. A formação social da mente: O desenvolvimento dos processos psicológicos superiores. 5. ed. São Paulo: Martins Fontes, 1994.

\section{Endereço dos Autores:}

Sergio Bruno Freitas Saraiva

Rua Clarindo de Queiroz, 1740 - Centro

Fortaleza - CE - 60.035-130

Endereço Eletrônico: sergiobruno.ef@gmail.com

Braulio Nogueira de Oliveira

R. Felizardo, 750 - Jardim Botânico

Porto Alegre - RS - 90.450-190

Endereço Eletrônico: brauliono08@hotmail.com

João Lucas Pinto Matias

R. Ver. Nelson de Sousa Alencar - Veneza, Iguatu - CE - 63.500-000

Endereço Eletrônico: joaolucasef@gmail.com

Bérgson Nogueira de Oliveira

Av. Sen. Salgado Filho, 3000 - Lagoa Nova

Natal - RN - 59.078-970

Endereço Eletrônico: bergson.nogueira@hotmail.com

André Accioly Nogueira Machado

Av. Dr. Silas Munguba, 1700 - Campus do Itaperi

Fortaleza - CE - 60.741-000

Endereço Eletrônico: andre.accioly@uece.br

Antônio Ricardo Catunda de Oliveira

Av. Dr. Silas Munguba, 1700 - Campus do Itaperi 
Sergio Bruno F. Saraiva, Conhecimentos Ludopedagógicos na Aprendizagem...

Braulio Nogueira de Oliveira, João Lucas P. Matias,

Bérgson Nogueira de Oliveira, André A. Nogueira Machado e

Antônio Ricardo C. de Oliveira

Fortaleza - CE - 60741-000

Endereço Eletrônico: ricardo.catunda@uece.br 